\title{
Implementasi GPS (Global Positioning System) Pada Presensi Berbasis Android DI BMT Insan Mandiri
}

\author{
Syaiful Amrial Khoir ${ }^{1}$, Anton Yudhana ${ }^{2}$, Sunardi ${ }^{3}$ \\ 1,3Teknik Informatika, Teknik Elektro \\ ${ }^{2}$ Universitas Ahmad Dahlan \\ Syaiful1807048001@webmail.uad.ac.id¹ ${ }^{1}$,eyudhana@ee.uad.ac.id², sunardi@mti.uad.ac.id ${ }^{3}$
}

\begin{abstract}
Attendance is a document that represents each employee at the company or representative. Some of the challenges experienced by KSPPS BMT INSAN MANDIRI are marketing that is difficult to carry out attendance when coming out of the office because of increased marketing activities that are directly related to members / out-of-office expenses. Therefore the researcher got findings to solve the problem that occurred by making an Android-based online attendance application that can be connected directly with the sarver provided by the office. This application is equipped with the introduction of security and the use of manipulations made by employees, and this application is equipped with monitoring features so that marketing managers and managers can set marketing positions in realtime. In this study, researchers used HTML and PHP programming languages for web applications that use presence servers / data centers, webside uses Google map APIs to obtain marketing positions, and presence reports can be purchased from the webside. The hope of this research is that the online android mobile attendance application with face recognition security can run well and meet the needs of the KSPPS BMT INSAN MANDIRI.
\end{abstract}

Keywords: Information Technology, Systems, Attendance, GPS, Android

\begin{abstract}
Abstrak
Absensi adalah dokumen yang mencatat kehadiran setiap karyawan pada suatu perusahaan atau instansi. Beberapa kendala yang dialami oleh KSPPS BMT INSAN MANDIRI yaitu marketing sulit untuk melakukan presensi hadir maupun saat keluar kantor karena tingginya aktifitas marketing yang berhubungan langsung dengan anggota / nasabah diluar kantor. Oleh karena itu peneliti mendapat gagasan untuk menyelesaikan masalah yang terjadi dengan membuat aplikasi absensi online berbasis mobile android yang dapat terhubung langsung dengan sarver yang dimiliki oleh kantor. Aplikasi ini dilengkapi security pengenalan wajah guna mengurangi penyalahgunaan dan manipulasi presensi oleh karyawan, serta aplikasi ini dilengkapi fitur monitoring sehingga manger marketing dan manager oprasional dapat memantau posisi marketing secara realtime. Dalam penelitian ini, peneliti menggunakan bahasa pemrograman HTML dan PHP untuk aplikasi web yang bertugas sebagai server / pusat data presensi, webside mengunakan Google map API untuk memantau posisi marketing, serta laporan presensi dapat dicetak dari webside. Harapan dari penelitian ini adalah aplikasi absensi online berbasis mobile android dengan security pengenalan wajah dapat berjalan dengan baik dan memenuhi kebutuhan KSPPS BMT INSAN MANDIRI.
\end{abstract}

Kata kunci : Teknologi Informasi, Sistem, Absensi, GPS, Android

\section{PENDAHULUAN}

KSPPS BMT INSAN MANDIRI adalah perusahaan yang bergerak dalam bidang perbankan dan berbadan hokum koperasi. Berkantor pusat di jl. Sukowati km. 01, Gemolong, Sragen dan memiliki 4 kantor cabang di seluruh 
wilayah jawa tengah. Sebagai upaya meningkatkan pemasaran produk, KSPP BMT INSAN MANDIRI mempunyai banyak karyawan dan 70\% dari jumlah karyawan adalah tenaga pemasaran yang terjun langsung ke lapangan untuk bertemu dengan anggota. Tenaga pemasaran harus sering keluar kantor dengan intensitas tinggi dan dengan rentang waktu yang tidak bisa ditentukan. Saat ini manajemen KSPPS BMT INSAN MANDIRI menerapkan aturan presensi kedatangan maupun kepulangan dengan menggunakan mesin absensi sidik jari bagi semua karyawan tanpa terkecuali termasuk tenaga pemasaran atau marketing. Dengan diterapkannya system absensi sidik jari, tenaga pemasaran kesulitan untuk melakukan presensi dikarenakan tenaga pemasaran dapat keluar masuk kantor dengan intensitas tinggi lebih dari 3 kali dalam satu hari kerja dengan rentang waktu 2 hingga 4 jam dalam 1 kali keluar kantor. Permasalahan yang sering muncul adalah tenaga pemasaran tidak sempat melakukan absensi karena kantor sudah tutup, dan lupa melakukan absensi akibat tingginya aktifitas tenaga pemasaran diluar kantor. Sehingga marketing atau tenaga pemasaran mendapatkan potongan gaji dan teguran dari manajer operasional.

Dengan adanya permasalahan tersebut peneliti menganggap perlu adanya suatu inovasi dan solusi dalam proses absensi. Sebagai upaya untuk menyelesaikan permasalahan yang terjadi peneliti membuat aplikasi absensi dengan menggunakan perangkat mobile Android dan teknologi pengenalan wajah sebagai securiti aplikasi dan Global Positioning System (GPS) untuk mendeteksi lokasi tenaga pemasaran atau marketing. Dengan adanya aplikasi ini, tenaga pemasaran atau marketing dapat melakukan absensi di seluruh wilayah kerjanya secara online dan tidak perlu lagi melakukan absensi secara manual menggunakan mesin absensi sidik jari, namun tenaga pemasaran hanya perlu membawa perangkat Android sebagai media untuk melakukan absensi. Aplikasi ini bekerja dengan mengenali wajah marketing untuk dapat masuk kedalam system absensi, serta mencatat kehadiran dan kepulangan marketing. Peneliti berharap dengan adanya aplikasi dan invoasi ini dapat mempermudah marketing dalam melaukan proses absensi dan meminimalkan kecurangan absensi dengan keamanan pengenalan wajah.

Dengan perkembangan teknologi yang semakin pesat saat ini, salah satunya adalah perkembangan teknologi komunikasi dengan smart phone. Smart phone memiliki banyak fitur didalamnya termasuk fitur GPS (Global Positioning System) dan fitur LBS (Location Based Service) untuk mengirimkan lokasi smart phone berada secara cepat dan akurat, maka dari itu penulis tertarik untuk mengembangkan sistem absensi berbasis smart phone khususnya Android [1]. Tujuan dari diadakannya penelitian ini adalah merancang bangun aplikasi absensi dengan keamanan pengenalan wajah, penggunaan teknologi GPS. (Global Positioning System), dan pembuatan laporan bulanan absensi, guna menyelesaikan permasalahan absensi sidik jari yang dialami oleh marketing atau tenaga pemasaran sehingga dengan aplikasi ini marketing dapat melakukan absensi dimanapun di area kerjanya. Selain itu tujuan untuk melakukan penelitian ini adalah untuk mempercepat 
proses absensi kehadiran maupun kepulangan karyawan sehingga dapat meningkatkan produktifitas dan pencapaian target produk [2].

\section{METODOLOGI PENELITIAN}

Aplikasi absensi tenaga marketing menggunakan metode location based service (LBS) berbasis Android di PT. Unichem Candi Indonesia. Aplikasi tersebut mampu melakukan absensi dengan memanfaatkan fitur GPS. (Global Positioning System), serta mampu mencatat kepulangan dan kehadiran karyawan. Sedangkan dari segi web aplikasi tersebut mampu memonitoring lokasi karyawan berada, mampu memanajemen data karyawan berupa data jabatan, data pribadi karyawan, rule absen, area kantor karyawan, mencetak laporan absensi, dan mencetak laporan presensi [3].

Dalam International Journal, penelitian yang dilakukan oleh Jan Nealbert V. Calimag, Pamela Anne G. Miguel, Romel S. Conde, dan Luisa B. Aquino dengan judul "Ubiquitous Learning Environment Using Android Mobile Application" pada tahun 2014. Penelitian ini bertujuan untuk memperkenalkan penggunaan lingkungan e-learning berbasis Android untuk beradaptasi dengan gaya belajar dari peserta didik abad ke-21. Sistem ini memberikan pembelajaran e-learning modern dengan memanfa'atkan aplikasi mobile berbasis android [4].

Dalam penelitian Jurnal Internasional yang dilakukan oleh Charalampos Doukas, Thomas Pliakas, dan Ilias Maglogiannis dengan judul "Mobile Healthcare Infromation Management Utilizing Cloud Computing Dan Android OS" pada tahun 2014. Penelitian ini bertujuan untuk memberikan informasi medis dimanapun dan kapan saja. Karena terdapat pemantau pasien, lokasi medis, tanggap darurat, dan layanan informasi masyarakat. Tidak hanya dapat digunakan pada komputer, dari android pun dapat diakses [4].

Dalam penelitian Jurnal yang dilakukan oleh Rifa 'Atunnisa, Eri Satria dan Rinda Cahyana dengan judul "Pengembangan Aplikasi Zakat Berbasis Android Menggunakan Metode Prototype" pada tahun 2014. Penelitian ini bertujuan untuk mempermudah setiap orang dalam membayar zakat melalui aplikasi mobile. Karena android juga sudah banyak digunakan dalam lapisan masyarakat maka dalam pengimplementasiannya sangat mudah dalam hal apapun termasuk berzakat [5].

Dalam penelitian Jurnal yang dilakukan oleh Taufik Ramadhan dan Victor G Utomo dengan judul "Rancang Bangun Aplikasi Mobile Untuk Notifikasi Jadwal Kuliah Berbasis Android" pada tahun 2014. Penelitian ini bertujuan untuk mempebaharui sistem terdahulu dengan aplikasi mobile yang berjalan pada android karena dalam hal penggunaan android lebih sangat efektif dan mudah [6].

Dalam penelitian Jurnal yang dilakukan oleh Eko Budi Setiawan dan Bobi Kurniawan dengan judul "Perancangan Sistem Absensi Kehadiran Perkuliahan Dengan Menggunakan Radio Frequency Identification (RFId)" pada tahun 2015. Penelitian ini bertujuan untuk meminimalisir kesalahan yang ada dilingkungan perkuliahan yang berhubungan dengan masalah 
absensi sehingga dibuatlah sistem absensi dengan menggunakan RFId karena sangat efektif dan efisien [7].

Dalam penelitian SKRIPSI yang dilakukan oleh Hartanto dengan judul "Perancangan Sistem Informasi Absensi Pegawai Dengan Barcode Scanner Card Pada Pt. Skyputra Pancasurya" pada tahun 2013. penelitian ini bertujuan untuk memperbaiki sistem absensi karyawan karena sistem yang masih manual menggunakan form kertas absensi yang akan di setorkan pada HRD untuk data. Oleh karena itu, peneliti menyarankan agar menggunakan barcode scanner dalam sistem absensi karena lebih mudah dalam pendataan absensi karyawan.

Dalam penelitian Tugas Akhir yang dilakukan oleh Eko Wijayanto dengan judul "Sistem Presensi Mahasiswa Dengan Fingerprint Berbasis Website" pada tahun 2017. Sistem presensi fingerprint bertujuan untuk menyingkat waktu pada saat proses pengambilan presensi. Selain itu, sistem akan mengurangi tingkat kecurangan mahasiswa terkait kehadiran mahasiswa. Dalam sistem ini, mahasiswa hanya akan diminta untuk mengunggah gambar sidik jarinya untuk menandai kehadiran mahasiswa. Pengembangan sistem ini menggunakan metode waterfall yang melibatkan integrasi dari berbagai teknologi open source berbasis website seperti MySQL, PHP dan Apache Web Server. Nantinya dalam sistem ini, dosen dapat mengetahui berbagai informasi terkait kehadiran mahasiswa. Hasil dari penelitian ini menunjukkan bahwa dengan menggunakan sistem ini dapat menyingkat waktu pada saat melakukan proses pengambilan presensi. Selain itu, mahasiswa juga tidak dapat lagi untuk melakukan kecurangan terkait kehadiran mahasiswa [8].

Dalam jurnal penelitian yang dilakukan oleh Reymon Rotikan dengan judul "Sistem Informasi Absensi Berbasis Web Untuk Kegiatan Konferensi" pada tahun 2016. Penelitian tentang sistem absensi berbasis Web dengan menggunakan Barcode yang dapat digunakan untuk setiap kegiatan konferensi. Pengembangan sistem absensi menggunakan metode Spiral yang memungkinkan pengembangan sistem secara sistematis dan iterative untuk setiap fiturnya. Hasil dari penelitian ini adalah sebuah sistem absensi yang dapat digunakan untuk mengambil absen di setiap sesi presentasi dalam sebuah kegiatan konferensi. Sistem juga dapat menampilkan laporan kehadiran untuk setiap sesi presentasi dan juga sesi presentasi yang paling diminati [9].

Dalam jurnal penelitian yang dilakukan oleh Wahyu Adam, M.Eng.Sc dan Lamhot Sagala dengan judul "Sistem Absensi Pegawai Menggunakan Teknologi RFID" pada tahun 2013. Penelitian ini bertujuan untuk merancang sebuah prototipe sistem absensi RFID yang terintegrasi dengan database untuk mendukung program peningkatan sikap displin karyawan sebagai langkah awal dari peningkatan kinerja kerja perusahaan secara keseluruhan. Prototipe RFID sistem absensi ini terdiri dari beberapa komponen utama, yaitu tag yang akan digunakan sebagai pengganti ID card dan reader yang digunakan untuk membaca informasi menyangkut kehadiran karyawan, 
integrasi database pada sistem ini akan memungkinkan dua untuk langsung disimpan secara otomatis ke dalam database.

Dalam jurnal penelitian yang dilakukan oleh Noval Aditya Muhammad, Febriliyan Samopa dan Radityo Prasetianto Wibowo dengan judul " Pembuatan Aplikasi Presensi Perkuliahan Berbasis Fingerprint" pada tahun 2013. Penelitian tersebut mengenai tentang sistem absensi berbasis fingerprint guna menunjang proses belajar mengajar, serta menanggulangi kecurangan presensi di kelas. Teknologi ini memang sedang marak dan sangat mendukung karena penerapannya tidak terlalu sulit lagipula terjangkau.Tetapi JSI belum memaksimalkan penerapan presensi fingerprint tersebut karena belum memiliki aplikasi yang mengelola presensi tersebut [10].

Dalam penelitian SKRIPSI yang dilakukan oleh Hartanto dengan judul "Perancangan Sistem Informasi Absensi Pegawai Dengan Barcode Scanner Card Pada PT. Skyputra Pancasurya" pada tahun 2013. penelitian ini bertujuan untuk memperbaiki sistem absensi karyawan karena sistem yang masih manual menggunakan form kertas absensi yang akan di setorkan pada HRD untuk data. Oleh karena itu, peneliti menyarankan agar menggunakan barcode scanner dalam sistem absensi karena lebih mudah dalam pendataan absensi karyawan.

Dalam jurnal penelitian yang dilakukan oleh Wahyu Adam, M.Eng.Sc dan Lamhot Sagala dengan judul "Sistem Absensi Pegawai Menggunakan Teknologi RFID" pada tahun 2013. Penelitian ini bertujuan untuk merancang sebuah prototipe sistem absensi RFID yang terintegrasi dengan database untuk mendukung program peningkatan sikap displin karyawan sebagai langkah awal dari peningkatan kinerja kerja perusahaan secara keseluruhan.Prototipe RFID sistem absensi ini terdiri dari beberapa komponen utama, yaitu tag yang akan digunakan sebagai pengganti ID card dan reader yang digunakan untuk membaca informasi menyangkut kehadiran karyawan, integrasi database pada sistem ini akan memungkinkan dua untuk langsung disimpan secara otomatis ke dalam database [11].

Dalam pengembangan perangkat lunak terdapat beberapa pendekatan atau metode yang digunakan, dalam penelitian ini metode yang digunakan adalah Extreme Programming (XP) untuk membangun aplikasi presensi berbasis Android. Extreme Programming (XP) merupakan sebuah proses rekayasa perangkat lunak yang cenderung menggunakan pendekatan berorientasi objek dan sasaran dari metode ini adalah tim yang dibentuk dalam skala kecil sampai medium serta metode ini juga sesuai jika tim dihadapkan dengan presensi yang berubah secara cepat. 


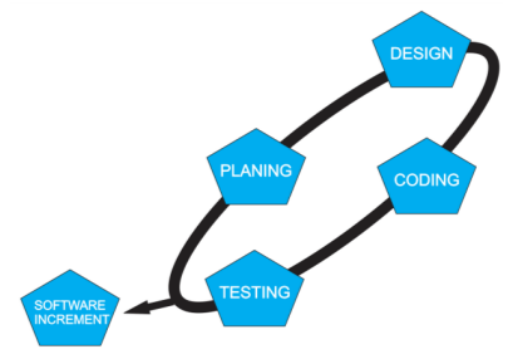

Gambar 1. Skema XP practices

Adapun tahapan pembangunan aplikasi presensi berbasis Android dengan XP adalah sebagai berikut:

\section{a. Planning (Perencanaan)}

Tahapan ini dimulai dengan mendengarkan kumpulan kebutuhan aktifitas suatu sistem yang memungkinkan pengguna memahami proses bisnis untuk sistem dan mendapatkan gambaran yang jelas mengenai fitur utama, fungsionalitas dan keluaran yang diinginkan. Dalam pembangunan aplikasi presensi berbasis Android pada tahapan ini dimulai dari mengidentifikasi permasalahan yang timbul pada sistem yang sedang berjalan, kemudian dilakukan analisa kebutuhan pengguna terhadap sistem yang akan dibangun.

\section{b. Design (Perancangan)}

Pada tahapan perancangan dilakukan pembuatan pemodelan sistem berdasarkan hasil analisa kebutuhan yang didapatkan. Selain itu dibuatkan juga pemodelan basis data untuk menggambarkan hubungan antar data. Pemodelan sistem yang digunakan yaitu Unified Modelling Language (UML) yang terdiri dari beberapa diagram antara lain Use-Case Diagram, Activity Diagram, Component Diagram dan Deployment Diagram. Sedangkan untuk pemodelan basis data menggunakan Entity Relationship Diagram (ERD) dan Logical Record Structure (LRS).

\section{c. Coding (Pengkodean)}

Tahapan ini merupakan implementasi dari perancangan model sistem yang telah dibuat kedalam kode program yang menghasilkan prototipe dari perangkat lunak. Dalam pembangunan aplikasi presensi berbasis Android menggunakan bahasa pemrograman Java, dan $\mathrm{C}++$, pembuatan aplikasi versi web yang akan digunakan oleh admin menggunakan bahasa pemrograman PHP yang dikombinasikan dengan HTML, CSS dan Javascript. Untuk implementasi basis data, Database Management System yang digunakan adalah MySQL.

\section{d. Testing (Pengujian)}

Tahapan ini merupakan tahapan pengujian terhadap aplikasi yang sudah dibangun, pada tahapan ini ditentukan oleh pengguna sistem dan 
berfokus pada fitur dan fungsionalitas dari keseluruhan sistem kemudian ditinjau oleh pengguna sistem. Metode yang digunakan dalam melakukan pengujian terhadap aplikasi web seleksi peserta pelatihan kerja ini adalah Black-Box Testing dengan melakukan pengujian terhadap masukkan dan keluaran yang dihasilkan sistem.

\section{e. Software Increment (Peningkatan Perangkat Lunak)}

Tahapan ini merupakan tahap pengembangan sistem yang sudah dibuat secara bertahap yang dilakukan setelah sistem diterapkan dalam organisasi dengan menambahkan layanan atau konten yang mengakibatkan bertambahnya kemampuan fungsionalitas dari sistem.

\section{HASIL DAN PEMBAHASAN}

Sistem absensi ini akan bekerja secara onlie dengan memanfaatkan Android dan internet sebagai alat untuk melakukan absensi dan web server sebagai pusat data absensi, sehingga sistem ini akan memudahkan marketing atau tenaga pemasaran dalam melakukan absensi, karena absensi dapat dilakukan diamana saja selama marketing berada di wilayah kerjanya dan absensi dapat dilakukan kapan saja oleh marketing. Dengan hadirnya sistem ini diharapakan perusahaan mampu berkembang dengan maksimal karena dengan menggunakan sistem absensi online ini akan dapat meningkatkan pengawasan secara online terhadap pergerakan marketing atau tenaga pemasaran saat berada di luar kantor melalui GPS (Global Positioning System). Sistem akan mampu mempermudah dan mempercepat proses absensi bagi karyawan karena hanya merlukan Android dan internet untuk dapat melakukan absensi dan tidak perlu melakukan absensi manual dengan datang kekantor kemudian melakukan scan sidik jari. serta akan mempermudah perusahaan dalam memantau lokasi marketing dan membuat laporan absensi marketing dengan mudah, karena sistem ini akan mampu membuat laporan yang akurat.

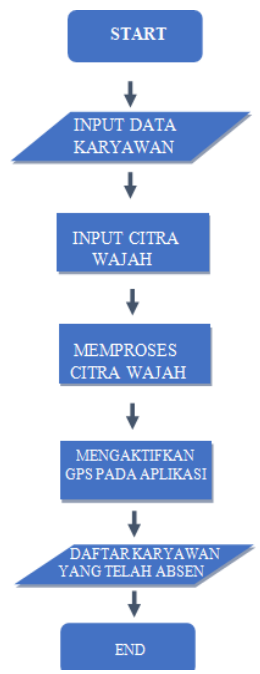

Gambar 2. Flowchart Presensi Karyawan dengan Aplikasi 
Keterangan gambar 2:

a. Input data karyawan adalah menginputkan data karyawan yang akan melakukan absensi.

b. Input citra wajah adalah proses memasukan citra wajah ketika karyawan hendak login kedalam aplikasi.

c. Proses citra wajah adalah untuk menentukan atau mengenali citra wajah yang telah dimasukkan.

d. Mengaktifkan GPS pada aplikasi untuk mengetahui posisi karyawan saat melakukan absensi.

e. Setelah karyawan berhasil melakukan absensi, data hasil absensi akan disimpan kedalam table database.

\section{SIMPULAN}

Sistem absensi onlie yang akan dikembangkan oleh penulis akan menggunakan sistem operasi Android untuk mempermudah proses presensi kedatangan maupun kepulangan marketing atau tenaga pemasran, sistem ini akan dibuat dengan GPS guna mengurangi kecurangan atau manipulasi presensi oleh marketing atau tenaga pemasaran. Dan bagi perusahaan sistem ini akan mampu mempermudah perusahaan dalam melakukan pengawasan terhadap marketing atau tenaga pemasaran dan akan mempermudah pembuatan laporan presensi bulanan oleh perusahaan.

\section{DAFTAR PUSTAKA}

[1] H. P. Utama, O. D. Nurhayati, and I. P. Windasari, "Pembuatan Aplikasi Memantau Lokasi Anak Berbasis Android Menggunakan Location Based Service," J. Teknol. dan Sist. Komput., vol. 4, no. 1, p. 202, 2016, doi: 10.14710/jtsiskom.4.1.2016.202-208.

[2] A. Husain, A. H. A. Prastian, and A. Ramadhan, "Perancangan Sistem Absensi Online Menggunakan Android Guna Mempercepat Proses Kehadiran Karyawan Pada PT. Sintech Berkah Abadi," Technomedia, vol. 2, no. 1, p. 119, 2017.

[3] N. H. Hutagaol, H. Kurniawan, and F. Chahyadi, "Aplikasi Absensi Tenaga Marketing Menggunakan Location Based Service (LBS) Berbasis Android," 2014.

[4] C. Doukas, T. Pliakas, and I. Maglogiannis, "Mobile healthcare information management utilizing Cloud Computing and Android OS," 2010 Annu. Int. Conf. IEEE Eng. Med. Biol. Soc. EMBC'10, pp. 1037-1040, 2014, doi: 10.1109/IEMBS.2010.5628061.

[5] R. C. Rifa'atunnisa, Eri Satria, "PENGEMBANGAN APLIKASI ZAKAT BERBASIS ANDROID MENGGUNAKAN METODE PROTOTYPE," Pengemb. Apl. ZAKAT Berbas. ANDROID MENGGUNAKAN Metod. PROTOTYPE, pp. 481-485, 2014, doi: 10.1109/AQTR.2012.6237759.

[6] V. G. U. Taufik Ramadhan, "Rancang Bangun Aplikasi Mobile Untuk Notifikasi Jadwal," J. Teknol. Inf. dan Komunikasi, , vol. 5, pp. 47-55, 2014, doi: 10.1234/JTIK.V5I2.93.

[7] E. B. Setiawan and B. Kurniawan, "Perancangan Sistem Absensi Kehadiran Perkuliahan dengan Menggunakan Radio Frequency Identification ( RFId )," 
CoreIT,Vol.1,No.2, Desember 2015, vol. 1, no. 2, pp. 44-49, 2015, doi: 10.1186/1756-3305-3-27.

[8] E. Wijayanto, "Sistem Presensi Mahasiswa Dengan Fingerprint," Naskah Pubilkasi Univ. Muhammadiyah Surakarta, 2017.

[9] R. Rotikan, "Sistem Informasi Absensi Berbasis Web Untuk Kegiatan Konferensi Web-Based Information System Attendance to Activity Conferences," J. Ilm. Sisfotenika, vol. 6, no. 1, pp. 46-55, 2016, doi: http://dx.doi.org/10.30700/jst.v6i1.104.

[10] N. A. Muhammad, F. Samopa, R. Prasetianto Wibowo, N. Rismawati, B. S. Eko, and K. Bobi, "Sistem Absensi Dosen Menggunakan Near Field Communication ( Nfc ) Technology," Fakt. Exacta, vol. 1, no. 2, pp. 44-49, 2013.

[11] M. E. S. Wahyu Adam, "Sistem absensi menggunakan teknologi rfid," Sist. Absensi Pegawai Menggunakan Teknol. RFID, pp. 1-6, 2013, doi: 10.1007/s10530-011-0092-x. 